\title{
Evaluation of Violet Plant (Securidaca longepedunculata) Roots as an Emulsifying Agent.
}

\author{
${ }^{1}$ Agu M. O, ${ }^{2}$ Barminas J.T, \\ ${ }^{1}$ Department of Science Laboratory Technology, Federal Polytechnic, Bali, Taraba State, Nigeria. \\ ${ }^{2}$ Department of Chemistry, Modibbo Adama University of Technology, Yola, Adamawa State, Nigeria.
}

\begin{abstract}
The Violet tree as it is called is scientifically identified as Securidaca longepedunculata from the family polygalaceae. It is called in Hausa as Sanya. This study investigated the emulsifying power of Violet Plant Root (VPR). This paper discusses the emulsion formation /capacity of VPR at different concentrations of 1 $\mathrm{g} / 100 \mathrm{ml}, 2 \mathrm{~g} / 100 \mathrm{ml}, 4 \mathrm{~g} / 100 \mathrm{ml}$ and $6 \mathrm{~g} / 100 \mathrm{ml}$. The emulsion capacity of two other synthetic detergents (called Samples $A$ and B) were studied and compared with that of VPR at the same concentration rate. In all, it was observed that the emulsion formation/capacity of VPR showed better creaming behavior than Samples $A$ and $B$ and the creaming stability gradually decreases in VPR but faster in Samples A and B. The emulsion formation/capacity of VPR at $1 \mathrm{~g} / 100 \mathrm{ml}$ concentration was higher than that of Samples $A$ and $B$. At concentration of $1 \mathrm{~g} / 100 \mathrm{ml}$ and determination time of $0.5 \mathrm{~h}$ to $48 \mathrm{~h}$, VPR, Samples A and B the emulsion formation was at the range of $98.40 \%$ to $70 \%$; $96.70 \%$ to $64.17 \%$ and $98.30 \%$ to $65.00 \%$ respectively. For 2 $\mathrm{g} / 100 \mathrm{ml}$ concentration and at the same time frame as in $1 \mathrm{~g} / 100 \mathrm{ml}$ VPR exhibited also a higher emulsion formation/capacity than Samples A and B with a range of $97.50 \%$ to $63.30 \%$; $96.70 \%$ to $60.00 \%$ and $95.00 \%$ to $56.60 \%$ for VPR, Samples A and B respectively. For $4 \mathrm{~g} / 100 \mathrm{ml}$ concentration, VPR, Samples A and B had a range of emulsion formation/ capacity of $93.30 \%$ to $61.60 \%$; $91.60 \%$ to $48.30 \%$ and $95.00 \%$ to $50.00 \%$ respectively for $0.5 \mathrm{~h}$ to $48 \mathrm{~h}$ determination time. For $6 \mathrm{~g} / 100 \mathrm{ml}$ concentration, VPR, Samples A and B also had an emulsion formation/capacity range of $91.70 \%$ to $66.70 \%$; $98.30 \%$ to $63.30 \%$ and $85.80 \%$ to $62.50 \%$ respectively within the time frame of $0.5 \mathrm{~h}$ to $48 \mathrm{~h}$. On observation of emulsion formation/capacity at different concentrations there is an indicates that VPR is a good emulsifier as it promotes emulsion formation at low and high concentrations and also VPR shows a better emulsion stability at different concentration than Samples A and $B$ on storage over a long period of over six months.
\end{abstract}

Keywords: VPR, emulsion, capacity, concentration.

\section{Introduction}

Violet Plant as a matter of fact, has many traditional and pharmaceutical applications and the usage varies in different areas (Arbonnier 2004). The cleansing property or action of detergents depends on its physical and chemical properties. Based on this Sharma (2006) enumerated some factors that are of great importance in deciding the cleansing action of detergent as; emulsifying power, adsorption, surface tension, electrostatic forces of the polar Soap molecules, wetting action etc.

According to Walstra (1993) an emulsion may be seen as heterogeneous system containing two immiscible liquid phases in which one is dispersed in the other as droplets (varies between $0.1-50 \mu \mathrm{m}$ in diameter). As the majority of emulsion contain water as one of the phase, it is customary to classify emulsion into two types the oil- in -water $(\mathrm{o} / \mathrm{w})$ type consisting of droplet of oil dispersed in water and water - in - oil (w/o) consisting of droplet of water dispersed in oil. This is the reason that made (Mill 1997) to refer emulsion as a dispersion of one liquid in a second immiscible liquid. A stable emulsion consisting of two pure liquids that cannot be separated; to achieve stability a third component, an emulsifying agent must be present generally. During formation of emulsion there is a kinetic competition involving many different processes. The principal processes include the formation of new oil/water interfaces as large droplets are subjected to shearing forces that break them into smaller droplets; diffusion of surfactants (small molecules and proteins) to the interface; surfactant adsorption, adhesion and coalescence of small droplets, often driven together by similar shearing forces to those that created them (Dickinson,1988). Also during stabilization of emulsion, (Dickinson, 1988) puts it as the stability of any lyophobic colloidal; suspension depends on the presence of a potential energy barrier to adhesion of the particles. Factors required for establishing such a barrier is in general an attraction between the suspended particles arising from the ubiquitous Van der Waals forces. In competition with this attraction, there are repulsive forces arising from various sources; in particular, the charge at the surface of the particle and "steric" interactions. Hawskins, (1997) puts it that stabilizers are substance that tends to maintain the physical and chemical properties of a material but have a single chemical component (or mixture) that confers long term emulsion stability possibly by an adsorption mechanism. For Dickson (2003) stabilizers are normally biopolymers or surfactants but small molecular weight surfactant, surface are not so effective in 
conferring long term stability. Darling and Birketti (1987) points out the difference between the concept of an "emulsion stabilizer" and that of an "emulsifier" as emulsifier promotes the formation of an emulsion while an emulsion stabilizer maintains the stability of the emulsion over a long period. Surface active substances (surfactants) can increase the kinetic stability of emulsions so that the emulsion does not change significantly over time. Emulsion stability is also referred to as the ability of an emulsion to resist change in its properties over time. Garrett (1997) writes that it must not be forgotten that water- soluble polymeric substances such as the gums, mucilage, saponins and proteins may also be excellent emulsifying agents. Introduction of an emulsifying agent lowers the interfacial tension of the two phases. Sharma et. al, (1999) puts it that emulsifying agent reduces the interfacial tension and the most commonly used emulsifying agent is Soap.

Violet Plant is scientifically identified as Securidaca longependunculata from the family polygalaceae. It is a common small tree or shrub in Sudanese and Guinean savannah country. In moist areas it is found on ironstone and rocks while in dryer areas it is found on riverbanks (Arbonnier, 2004). It is readily recognized by its brilliant purple (occasionally white) flowers and by the dry wrinkled fruits ending in a broad flat wing about $5 \mathrm{~cm}$ long. (Keay, 1989). The tree produces seeds that are irregularly wrinkled, more or less flat. It flowers between February to May which are distinctly ornamental. It is popularly known and called in Hausa as Sanya or Uwar magunguna (literally called in English Mother of Medicine). It is a shrub mostly found in both North and Southern Nigeria. The Yoruba call it Epeta while it is called Alali in Fulfulde. Other parts of West African countries like Ashanti in Ghana call it Ofodo, Gambians call it Juto while Sierra Leonians call it Yodo or Jodo (Dalziel 1937). Apart from the traditional uses of S. longepedunculata roots as; purgative, violent sneezing if powdered, bleaching cloth etc. it can also be used in the treatment of ailments like cough, urethral discharge, catarrh, fever, analgesic, for especially headache, itching, treatment of constipation and stomach ache in women before child birth, tooth decay, internally injected for Syphilis infection (dangerous if taken in large quantity), rheumatic pain reliever and stiffness, etc. (Delziel 1937)

\section{Materials}

\section{Materials and Methods.}

The Roots of Violet Plant (Securidaca longependunculata) were obtained from Girei in Girei Local Government Area of Adamawa State. The Roots were washed to remove sand and dirt. The smooth thick bark of the Root was peeled, cut into small pieces and kept in the laboratory at room temperature $\left(30^{\circ} \mathrm{C}\right)$ for one week to dry. Later, the roots were pulverized to a reasonable size with pestle and mortar (metallic type) and sieved from where surfactant solution was prepared. The synthetic/commercial detergent (i.e. Sample A and B) was purchased from the market in Jimeta Adamawa State.

\section{Chemicals and Materials}

Paraffin Oil, Distilled De-ionized water, Samples (Violet Plant Root (VPR), Sample A and B), $60 \mathrm{ml}$ Glass Syringe, $250 \mathrm{ml}$ Beaker, $100 \mathrm{ml}$ Measuring Cylinder, Analytical Digital Balance (GR-200-EC), Endecotts Sieve with Mechanized Shaker, Stop Watch, and Meter rule.

\section{Emulsion formation/capacity}

\section{Method}

Emulsion was prepared by mixing $30 \mathrm{ml}$ paraffin oil and $30 \mathrm{ml}$ sample solution in a $250 \mathrm{ml}$ Beaker. The mixture was homogenized using an improvised method of $60 \mathrm{ml}$ glass syringe. This improvised homogenization process involved repeated cycles of sucking and rapid expulsion of emulsion from the syringe. This was done to ensure proper droplet break-up until a creamy homogenous emulsion was obtained.

Emulsion capacity was expressed as the amount of oil emulsified and held per gram of Sample (Padmashree et. al, 1987). The Emulsion Capacity was calculated using the established mathematical formula stated below.

\section{Emulsion Capacity $=\mathrm{X} / \mathrm{Y} \times 100 \%$ \\ Where $\mathbf{X}=$ Height of emulsified layer \\ $\mathbf{Y}=$ Height of whole solution.}

The different concentrations of surfactant solutions of VPR, Sample A and B was made for example: $1 \mathrm{~g} / 100$ $\mathrm{ml}, 2 \mathrm{~g} / 100 \mathrm{ml}, 4 \mathrm{~g} / 100 \mathrm{ml}$, and $6 \mathrm{~g} / 100 \mathrm{ml}$ so that their emulsifying activities could be studied over an interval of time, say ; $0.5,1,2,3,4,5,6,24$, and 48 hours.

\section{Results And Discussion}

Stable emulsion was formed with a surfactant solution to oil in a ratio of 1:1 (volume: volume) using an improvised method of a $60 \mathrm{ml}$ glass syringe. At different concentrations of the Violet Plant Root (VPR) a creamy substance of oil - in - water emulsion was observed. All the surfactant solutions exhibited high emulsifying activities or capacity (EC) at different concentrations. Shown below in figure 1a is a graph of 
emulsion capacity for $1 \mathrm{~g} / 100 \mathrm{ml}$ concentration of the surfactant solution (VPR, Sample A and B) at different time intervals.

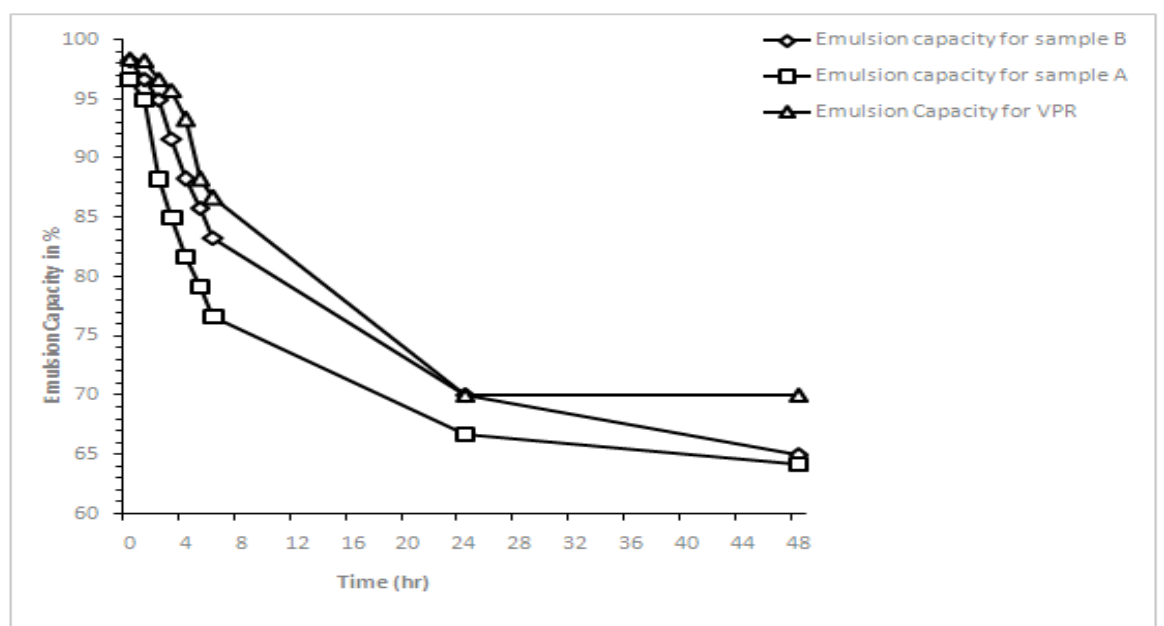

Figure.1a: Plot of emulsion capacity (\%) versus Time (h) for $1 \mathrm{~g}$ of Surfactant solutions.

The emulsion capacity of VPR at $1 \mathrm{~g} / 100 \mathrm{ml}$ concentration from the graph was higher than that of Sample A and B from $0.5 \mathrm{~h}$ to $48 \mathrm{~h}$ determination time. VPR was in the range of $98.40 \%$ to $70.00 \%$ emulsion capacity while Samples A and B were at $96.70 \%$ to $64.17 \%$ and $98.30 \%$ to $65.00 \%$ respectively. In fact, the VPR at different concentrations showed better creaming behavior than Samples A and B. However, on storage it was observed that the creaming stability gradually decreases with VPR but faster in commercial surfactants (samples A and B). This may be as a result of droplet size distribution which depends on droplet break - up and not droplet formation (Dickinson, 1988).From literature, Garrett (1997) wrote that water soluble polymeric substances such as the gums, mucilage, saponins, and proteins may also be excellent emulsifying agents. This aspect of the literature provides the proof that VPR is an excellent emulsifying agent as it contains saponins.

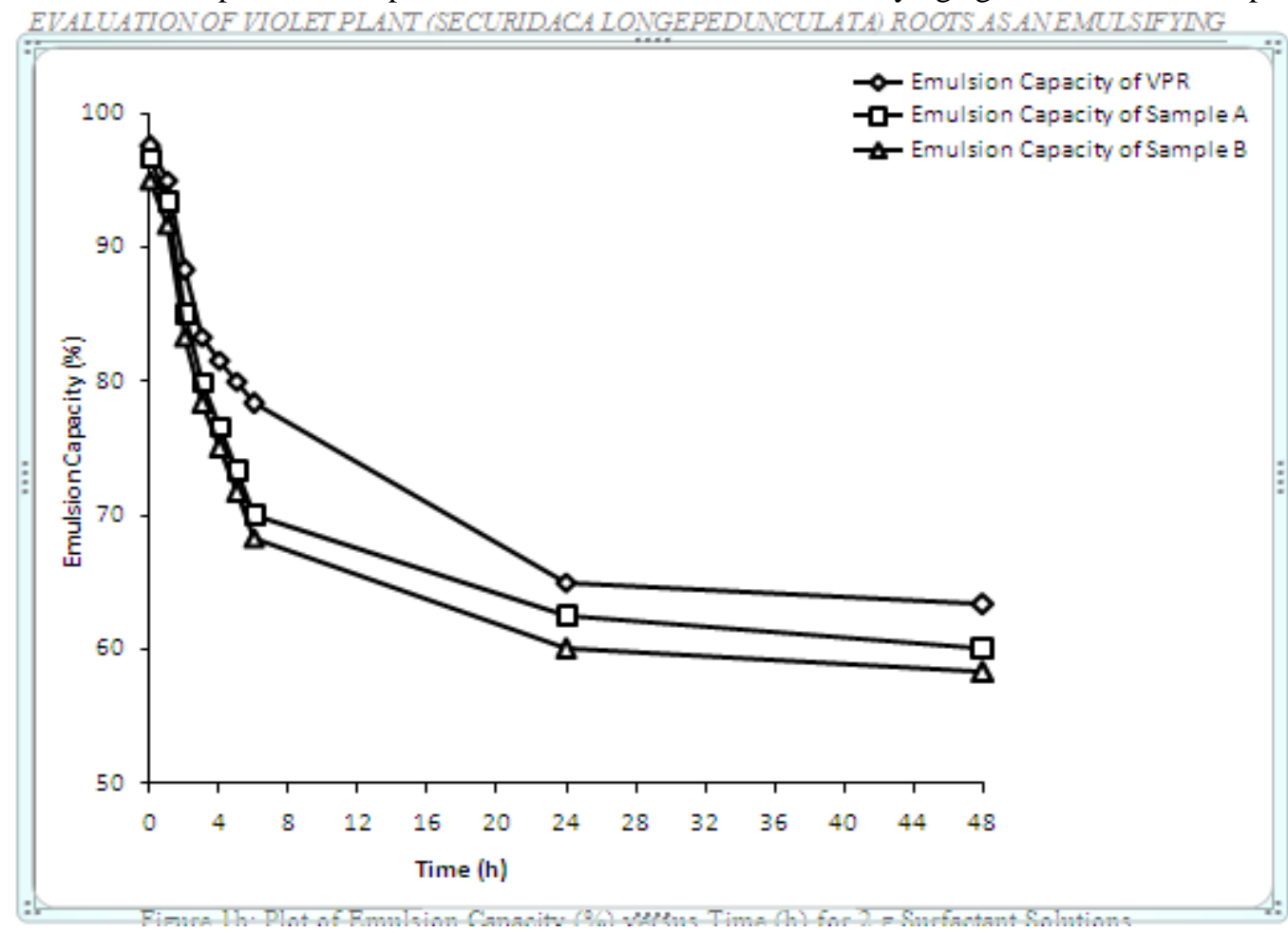

Figure.1b: Plot of Emulsion Capacity (\%) versus Time (h) for 2 g Surfactant Solutions.

The emulsifying activities of the surfactant solutions of VPR, Samples A and B at $2 \mathrm{~g} / 100 \mathrm{ml}$ concentration was studied over a period of time which ranged from $0.5-48 \mathrm{~h}$. Similar, to the result obtained at $1 \mathrm{~g}$ concentration of the surfactant solutions; the VPR exhibited also a higher emulsion capacity than Samples A and $\mathrm{B}$ of the commercial surfactants. The range was $97.50 \%$ to $63.30 \% ; 96.70 \%$ to $60.00 \%$ and $95.00 \%$ to 56.60 
$\%$ for VPR Samples A and B respectively for the time range of $0.5 \mathrm{~h}$ to $48 \mathrm{~h}$. The pictorial representation is as shown in figure $1 \mathrm{~b}$.

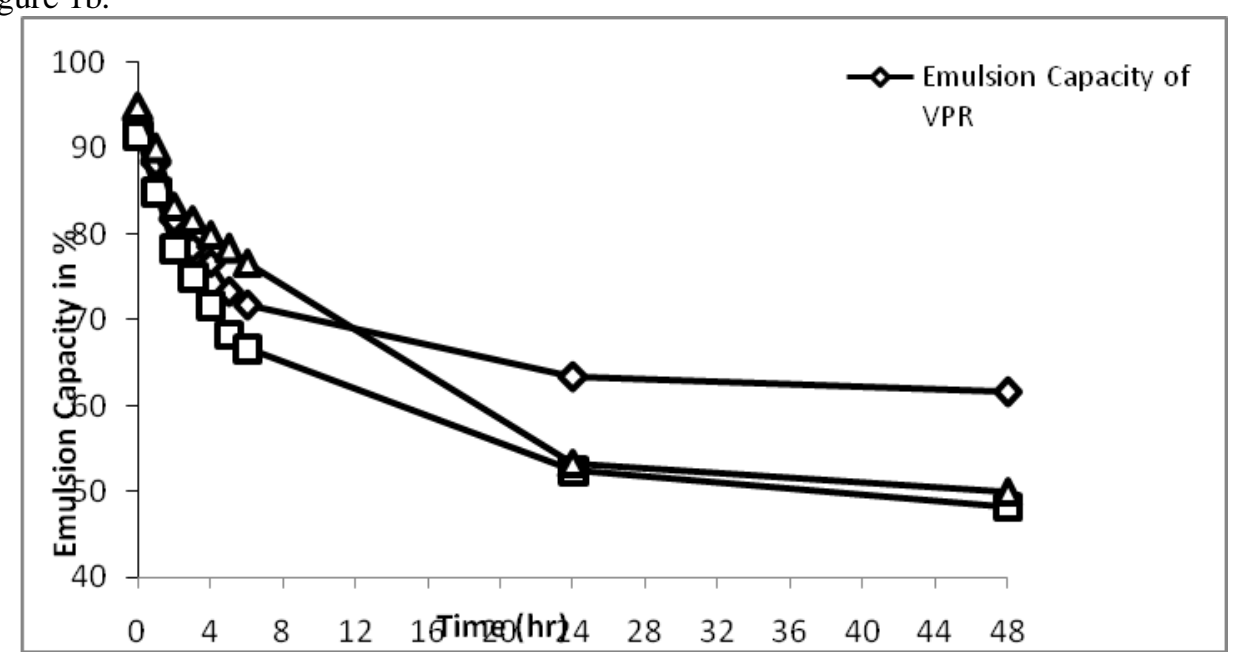

Figure.1c: Plot of Emulsion Capacity (\%) versus Time (h) for $4 \mathrm{~g}$ Surfactant Solutions.

At $4 \mathrm{~g} / 100 \mathrm{ml}$ concentration of the surfactant solutions the result obtained shows that VPR exhibited higher emulsion capacity which may indicate better emulsifying material than the others with a result ranging from $93.30 \%$ to $61.60 \%$ between 0.5 to $48 \mathrm{~h}$. At the same time range, Sample A and B has emulsion capacity of $91.60 \%$ to $48.30 \%$ and $95.00 \%$ to $50.00 \%$ respectively.

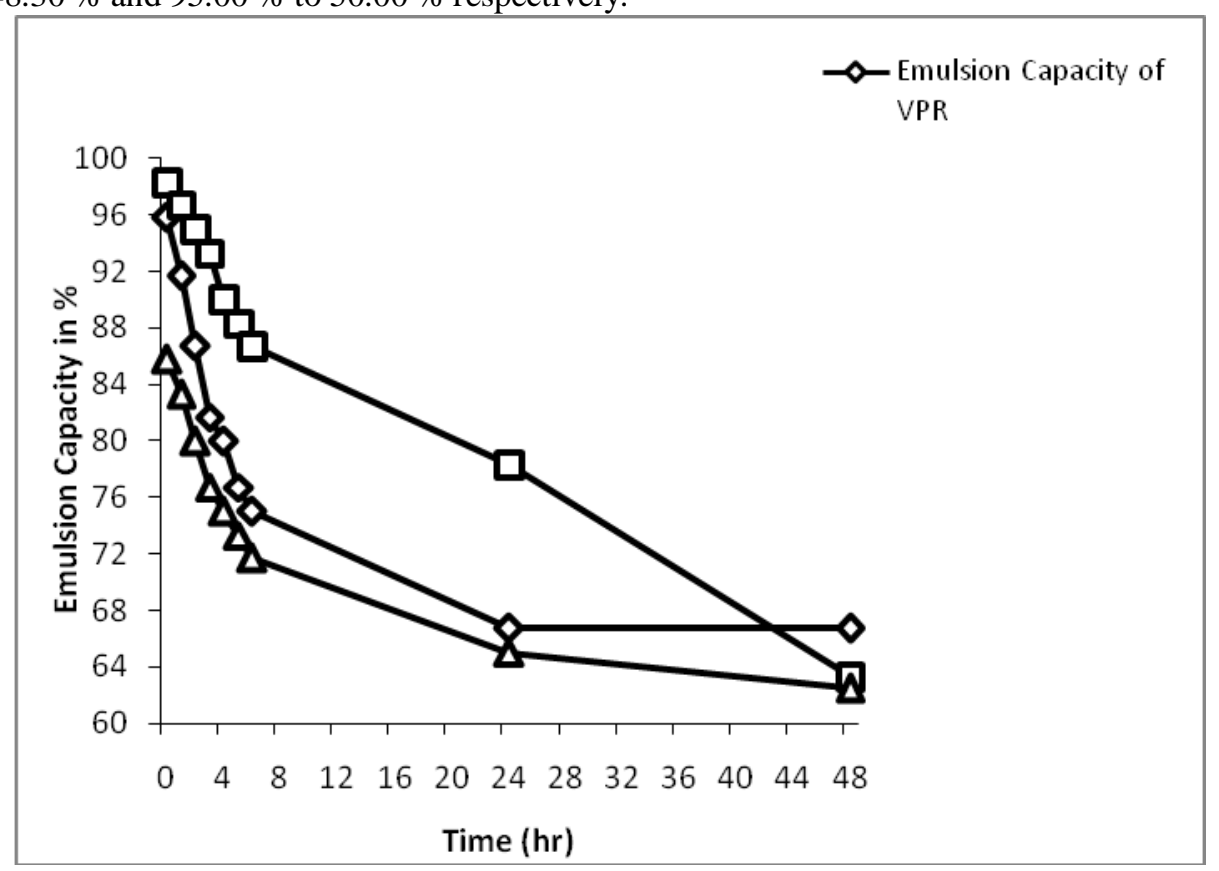

Figure.1d: Plot of Emulsion Capacity (\%) versus Time (h) for $6 \mathrm{~g}$ Surfactant Solutions.

Similarly, the plot of emulsion capacity with time for $6 \mathrm{~g}$ surfactant solutions shows that VPR at higher concentration can exhibit good emulsifying property. The study at $6 \mathrm{~g}$ surfactant solution shows that VPR has a range of 95.8 to $66.7 \%$ emulsion capacity as compared to 98.3 to $63.3 \%$ and 85.8 to $62.5 \%$ emulsion capacity of Samples A and B respectively. A good emulsifying agent therefore must be surface active, that is, it must have the capacity to lower the surface tension at the oil - water interface, both substantially and rapidly when present at the concentrations typically used during emulsification. Dickson (2003) indicated that the lower the interfacial tension the greater the extent to which droplets can be broken up during intense shearing or turbulent flow.

The stability achieved at different concentrations of the surfactant solutions was as a result of VPR, Sample A and B that acts as emulsifying agent. Mill (1997) writes that to achieve stability in emulsion a third component an emulsifying agent must be present. The work of surfactants as emulsifier are characterized by the fact that they possess both a hydrophilic and a hydrophobic moiety and as a result of this structure they do orient themselves at oil - water or gas - water interface thereby reducing surface energy (Adebayo,2001). The graphs of studies carried out on Emulsion formation/capacity at different concentrations (i.e. figures 1a-d) may be used 
to establish the fact that Violet Plant Root (VPR) is a good emulsifier as it promotes emulsion formation at both low and high concentrations.

\section{Conclusion}

The studies conducted proves that Violet Plant Root (VPR) can be considered as a good emulsifier for its stabilization of oil-in-water (o/w) emulsions as it shows better creaming behavior than commercial surfactant like Sample A and B in both low and high surfactant concentrations. Emulsion formation/capacity for $1 \mathrm{~g}$ of the surfactant solution at $0.5 \mathrm{~h}$ and $48 \mathrm{~h}$ time range yielded $98.4 \%$ and $70 \%$ respectively. Also, at the same time range, the following but different of the same surfactant solutions $2 \mathrm{~g}, 4 \mathrm{~g}$ and $6 \mathrm{~g}$ yielded $97.5 \%$ and $63.3 \%$; $93.3 \%$ and $61.6 \%$; $95.8 \%$ and $66.7 \%$ respectively. Again, VPR shows a lasting creaming stability than Sample A and B of commercial surfactants, this was noticed on constant routine check of the emulsified products for a period of six months. It was found that at different concentration VPR proves to be good emulsifying agent as it is characterized by the fact that it possesses both a hydrophilic and a hydrophobic moiety.

This will offer some outlets for utilizing VPR as an emulsifying agent in many industrial applications. The results obtained could place VPR as an emulsifier with high amphiphilic power like many commercial petrochemical stabilizers.

\section{References}

[1]. Adebayo, J.S.(2001)Investigation into the emulsifying properties of Konkoli (Maesopsis eminii) B. Tech project Chemistry Department, Federal University of Technology, Yola,Nigeria.pp1.- 27.Arbonnier, M.(2004) Trees, Shrubs, and Lianas of West African Dry Zone, Cfra Margrat Publishers, GMBH, Netherland, pp435.

[2]. Dalziel, J.M (1937) The useful Plant of West Tropical African, Whitefriare Press Ltd, London pp27-28.

[3]. Darling, D.F. and Birketti R.J (1987) In Food Emulsions and Foams (ed. Dickinson E.), Royal Society of Chemistry, London, U.K. PP1-29.

[4]. Dickinson, E. and Stainsby G.(1988) Emulsion Stability. In: Advance in food emulsions and Foams. Dickinson E,.Stainsby G.(eds),Etsevier.1-44.

[5]. Dickson, E. (2003) 'Hydrocolloids at interfaces and the influence on the properties of dispersed system' Food Hydrocoll, 17 (1) pp25-37.

[6]. Fell, J.T(1988) Surface and Interfacial Phenomena: Pharmaceutics the science of Dosage from Design (Aulton, M.E, Editor) ISE Churchchill Livingstone, New York, pp60-61

[7]. Garrett, H.E.(1997) Surface Active Chemicals, Pergamon Press, New York pp30,32,34,44,47,51 -

[8]. Hawksins, W.L. (1997) 'Stabilizer' in: Encyclopedia of Science and Technology, 17(8 ${ }^{\text {th }}$ edition) 299-300

[9]. Keay, R.W.(1989) Trees of Nigeria, Clarendon Press, Oxford, New York,pp48

[10]. Mill, G.S and Millingan W.O(1997) 'Emulsion' In: McGraw Hill Encyclopedia of Science and Technology $8^{\text {th }}$ Edition $385-386$

[11]. Padmashere, T.S Vijayalakshmi L, Puttaraj S.J(1987) Food Science Technology vol. 24, Pp 221 - 225.

[12]. Sharma, B.K.(2006) Industrial Chemistry including Chemical Engineering, GOEL Publishing Home, Meerut.pp1244-1277.

[13]. Sharm, K.K, and Sharma L.K.(1999) A Textbook of Physical Chemistry, $4^{\text {th }}$ Edition, Vikas Publishing House PVT Ltd, New Delhi.Pp77-85.

[14]. Walstra, P. (1993) Principles of Emulsion Formation Chemical Engineering Science, Great Britain 48(2):333-349. 